\title{
Acoustic Monitoring of a Bottlenose Dolphin (Tursiops truncatus) Population: Trends in Presence and Foraging beyond the Limits of the Lower River Shannon SAC
}

\author{
Rachel Charish ${ }^{1, *(D)}$, Simon Berrow ${ }^{1,2}$ and Joanne $O^{\prime}$ Brien $1,2, *$ (D) \\ 1 Marine and Freshwater Research Centre, Galway-Mayo Institute of Technology, Old Dublin Road, \\ EC5 855G Galway, Ireland; simon.berrow@iwdg.ie \\ 2 Irish Whale and Dolphin Group, Merchants Quay, V15 E762 Kilrush, Ireland \\ * Correspondence: rocwolf89@gmail.com (R.C.); joanne.obrien@gmit.ie (J.O.)
}

Citation: Charish, R.; Berrow, S.; $\mathrm{O}^{\prime}$ Brien, J. Acoustic Monitoring of a Bottlenose Dolphin (Tursiops truncatus) Population: Trends in Presence and Foraging beyond the Limits of the Lower River Shannon SAC. J. Mar. Sci. Eng. 2021, 9, 650. https://doi.org/10.3390/jmse9060650

Academic Editor: Giuseppa Buscaino

Received: 12 May 2021

Accepted: 10 June 2021

Published: 12 June 2021

Publisher's Note: MDPI stays neutral with regard to jurisdictional claims in published maps and institutional affiliations.

Copyright: (c) 2021 by the authors. Licensee MDPI, Basel, Switzerland. This article is an open access article distributed under the terms and conditions of the Creative Commons Attribution (CC BY) license (https:/ / creativecommons.org/licenses/by/ $4.0 /)$.

\begin{abstract}
The Shannon dolphins are a population of bottlenose dolphins resident year round within the Lower River Shannon SAC, Ireland, which has been designated to protect this relatively small, genetically discrete population. Although trends in habitat use and foraging have been studied within the estuary, little is known about the movements of the Shannon dolphins outside the boundaries of the SAC, and whether any other foraging hotspots exist for this population outside of the estuary. The purpose of this study was to explore the presence and foraging behavior of these dolphins in adjacent waters located 20-30 km to the southwest of the Lower River Shannon SAC. Static acoustic monitoring was carried out with C-PODs deployed in Ballyheigue Bay, Brandon Bay, and around the Maharees between May and November 2013. A GEE-GLM modelling approach was then used to analyze potential significant environmental predictors of presence and foraging by bottlenose dolphins at these sites. Brandon Bay was found to be a site of particular importance for the Shannon population, where dolphins were present on $92 \%$ of days monitored and foraging occurring on $20 \%$ of all monitored hours. The results of this study indicate that Brandon Bay is a potentially important habitat for the Shannon dolphins and further support designation of this site as a candidate SAC. However, long-term acoustic monitoring should be conducted at all sites to identify relative use of the areas at year-round and inter-annual scales.
\end{abstract}

Keywords: acoustic monitoring; bottlenose dolphin; C-PODs; echolocation clicks; special area of conservation; Lower River Shannon SAC

\section{Introduction}

The Shannon dolphins are a genetically distinct population of bottlenose dolphins (Tursiops truncatus), consisting of approximately 145 individuals that are resident year round in the Shannon Estuary [1-3]. These dolphins have been present in the Shannon Estuary since at least 1835, and have been catalogued photographically by the Irish Whale and Dolphin Group since 1993 [4-8]. They are one of three genetically distinct populations of bottlenose dolphins in Irish waters, the other two being the Connemara-MayoDonegal (coastal) population and an offshore pelagic population [2-4]. The ConnemaraMayo-Donegal population and pelagic offshore population are mobile, with large-scale movements of up to $650 \mathrm{~km}$ reported [2,8]. In contrast, the Shannon population exhibits long-term site fidelity, and photo-identification data of the Shannon population shows no evidence of mixing with dolphins using other sites and almost exclusive use by the Shannon population of bays adjacent to the Shannon Estuary $[1,2,8]$.

Bottlenose dolphins are legally protected in Ireland under the Wildlife Act and its Amendment (2000), and also listed under Annex IV and Annex II of the EU Habitats Directive (92/43/EEC). Annex II imposes an obligation to designate Special Areas of Conservation (SAC) to protect the habitats of listed species, and to date Ireland has designated 
two SACs to fulfill its obligation to protect bottlenose dolphin habitats: the Lower River Shannon SAC and the West Connacht Coast SAC.

To protect the core habitat of the Shannon bottlenose dolphin population, the Lower River Shannon was designated as a candidate SAC in 2000 and incorporated into the Natura 2000 network [1]. Although the dolphin population appears to be stable, the Shannon Estuary is an area with significant economic and industrial activity [6]. Up to 1000 ships use the estuary annually, and as a result, the Shannon dolphins are exposed to a number of anthropogenic threats including acoustic disturbance, water contamination, entanglement and habitat degradation within the Lower River Shannon SAC [6,8-10].

The first study describing year-round trends in the presence and foraging by Shannon dolphins within the Lower River Shannon SAC was published by Carmen et al. [6] in 2021. Tidal cycle, season, diel phase, and tidal phase were all found to be significant predictors of dolphin presence and foraging within the Shannon Estuary [6,11]. Overall, the number of days with detections within the Shannon Estuary varied by site, declining with increasing distance from the mouth of the estuary. The highest number of detections $(71.2 \%$ of days monitored) were recorded at Moneypoint, in the middle part of the estuary, while dolphins were only detected on $15.9 \%$ of days monitored at Shannon Airport, in the inner estuary, which was the site with the least number of detections [6]. Boat-based surveys have revealed seasonal decreases in the presence of the Shannon Estuary dolphins in the outer estuary during winter, and the Lower River Shannon SAC is unlikely to represent the population's entire geographic range [3,6,12]. Dolphins have been sighted regularly in bays adjacent to the Shannon Estuary, such as Kilkee Bay $25 \mathrm{~km}$ to the north of the boundary of the SAC and Tralee and Brandon Bays located 20-30 km to the south [1,13]. During boat-based visual surveys carried out by Levesque et al. [1] in Brandon Bay and Tralee Bay between 2008 and 2016, bottlenose dolphins were observed on $90 \%$ of trips and $96 \%$ of the dolphins observed were matched through photo-identification to the Shannon population.

Although boat-based and aerial visual surveys are still the primary methods of monitoring cetacean populations in Ireland, acoustic monitoring provides certain advantages such as allowing data to be collected continuously over long periods of time, and during darkness or during adverse weather conditions that would otherwise impair visual detections $[14,15]$. This is particularly relevant for small, fast-moving cetacean species such as bottlenose dolphins, which may go visually undetected $87 \%$ of the time [11].

Acoustic monitoring can provide a level of detail on cetacean behavior and movements that would not typically be captured by brief surface observations [11,15]. Because of the extent of anthropogenic pressures that exist within the Lower River Shannon SAC and the potential for fine-scale variation in habitat use by bottlenose dolphins, it is important to understand whether there are additional sites near the Lower River Shannon SAC that are important foraging grounds for the Shannon population. The purpose of this study was therefore to expand upon the findings by Levesque et al. [1] who documented the significant occurrence of Shannon bottlenose dolphins in bays adjacent to, and outside the limits of, the Lower River Shannon SAC by using static acoustic monitoring to determine:

1. The presence of bottlenose dolphins in Ballyheigue Bay, Brandon Bay, and around the Maharees;

2. Whether these sites represent potential foraging habitats for bottlenose dolphins;

3. What the environmental drivers of bottlenose dolphin presence and foraging are in these locations.

The presence and feeding activity of bottlenose dolphins in these bays could warrant expanding the Lower River Shannon SAC to include foraging grounds outside the estuary.

Based on the results of the Levesque et al. [1] surveys as well as previous research showing fine-scale variation in habitat use by bottlenose dolphin populations within the Cardigan Bay SAC in Wales and the Moray Firth SAC in Scotland, it was hypothesized that bottlenose dolphins would be detected at the three study sites and that the drivers of presence and foraging would be site specific $[16,17]$. 
Trend analysis represents a useful tool in the environmental sciences for determining the environmental conditions that are associated with species presence and foraging over time [18-20]. Environmental cycles such as the seasonal, diel and tidal cycles lead to patterns in the behavior of prey species and marine top predators such as bottlenose dolphins [16]. An understanding of these patterns can inform conservation and management decisions about the appropriate boundaries for SACs and how these boundaries should evolve over time in response to range shifts and changes in prey availability $[16,21]$. This study aims to complement previous trend analysis of Shannon dolphin presence and foraging within the Lower River Shannon SAC by examining locations adjacent to the boundaries of the SAC.

\section{Materials and Methods}

\subsection{Data Collection}

C-PODS were deployed at Ballyheigue Bay, Brandon Bay, and the Maharees between May and November 2013. These locations are on the west coast of Ireland, at distances of approximately $10-30 \mathrm{~km}$ from the mouth of the Shannon Estuary (Figure 1). At each site, the C-PODs were suspended in the water column at mid-depth (5-10 $\mathrm{m}$ from the bottom). The schedule of deployments is presented in Table 1.

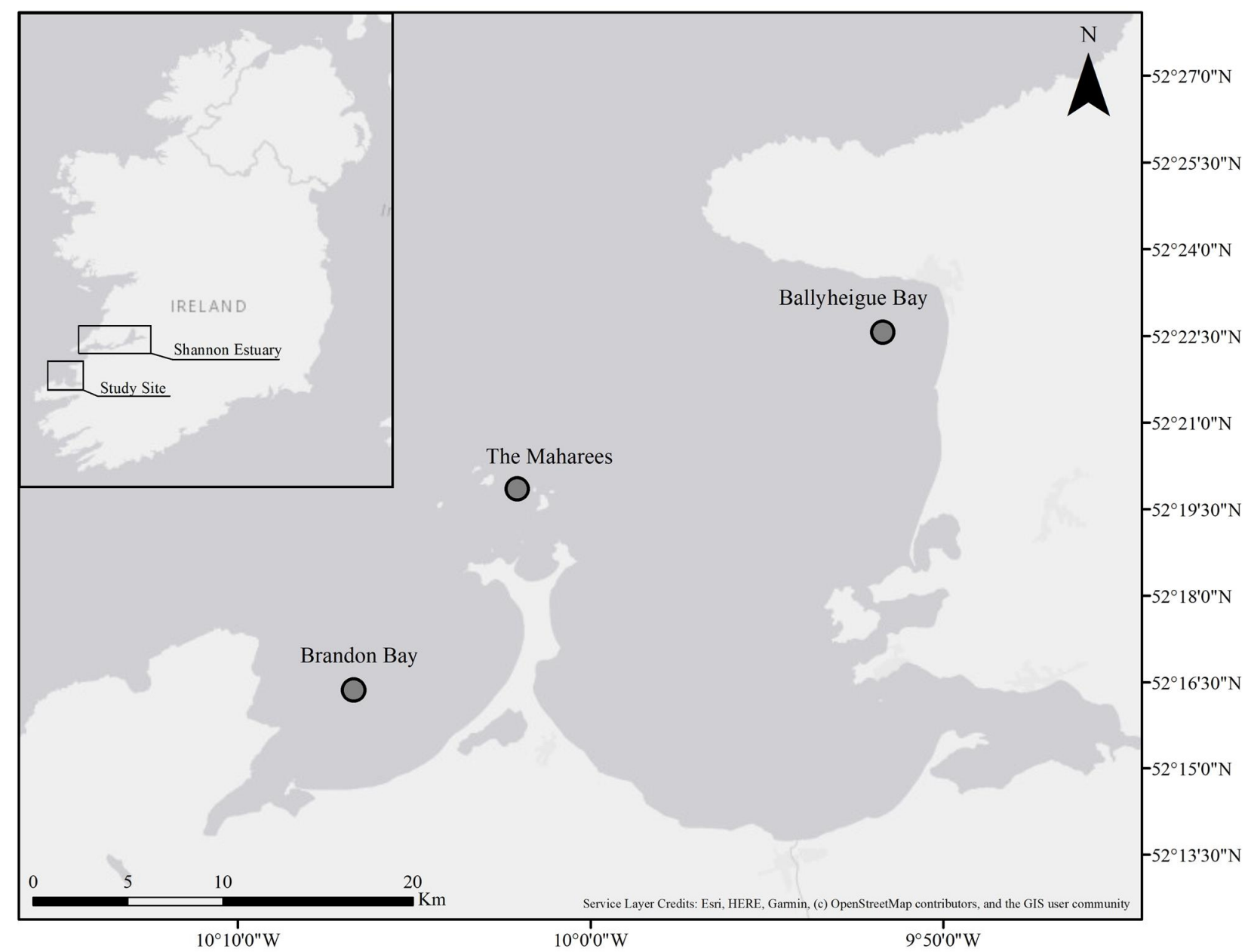

Figure 1. Map of the monitoring locations. C-PODs were deployed at Ballyheigue Bay, Brandon Bay and the Maharees, indicated by the grey circles. The Shannon Estuary (and the associated Lower River Shannon SAC) are located to the north of the study sites. 
Table 1. Summary of C-POD deployments in Ballyheigue Bay, Brandon Bay and the Maharees.

\begin{tabular}{ccccc}
\hline Study Location & C-POD ID & $\begin{array}{c}\text { Deployment } \\
\text { Start Date }\end{array}$ & $\begin{array}{c}\text { Deployment } \\
\text { End Date }\end{array}$ & $\begin{array}{c}\text { Total Number } \\
\text { of Days }\end{array}$ \\
\hline Ballyheigue Bay & 173 & $19 / 05 / 2013$ & $23 / 06 / 2013$ & 36 \\
Brandon Bay & 1525 & $25 / 05 / 2013$ & $22 / 07 / 2013$ & 59 \\
Brandon Bay & 2020 & $22 / 07 / 2013$ & $13 / 10 / 2013$ & 84 \\
Maharees & 1524 & $18 / 05 / 2013$ & $25 / 05 / 2013$ & 8 \\
Maharees & 547 & $22 / 07 / 2013$ & $13 / 11 / 2013$ & 115 \\
\hline
\end{tabular}

C-PODs (Chelonia Limited, Mousehole, Cornwall, United Kingdom) are static acoustic monitoring devices that can detect cetacean clicks in the $20-160 \mathrm{kHz}$ frequency range [22,23]. Bottlenose dolphins produce three categories of vocalization: (i) burst-pulse sounds, (ii) whistles, and (iii) broadband (30-150 kHz) clicks [15,24,25]. Whistles and burst-pulse sounds have a social function, while echolocation clicks are employed mainly in foraging and navigation [15,25-27]. C-PODs do not record burst-pulse sounds or whistles, and instead log only information about click trains [22,23]. Bottlenose dolphin feeding buzzes are short, fast echolocation click trains with minimum inter-click intervals (ICI, the amount of time between consecutive echolocation clicks) between 3.0 and $7.1 \mathrm{~ms}[15,28]$. As a result, click trains with a minimum ICI length of $<10 \mathrm{~ms}$ have been used as a proxy for foraging by bottlenose dolphins in various studies $[15,28]$. Because one of the click train parameters logged by C-PODs is the ICI, it is possible to infer behavioral states such as foraging [6].

In contrast to bottlenose dolphins, harbor porpoise vocalizations consist only of click trains where the clicks are concentrated over the narrow range of frequencies from 120 to $150 \mathrm{kHz}$ [29-31]. The length of the ICI in harbor porpoise click trains can also be used to infer behavioral state [32]. When harbor porpoises are navigating, the ICI tends to be $50-60 \mathrm{~ms}$, whereas during predation, the ICI decreases and concludes with a terminal buzz that has an ICI of 1.4-1.6 ms [15,33,34].

When clicks are detected by a C-POD, the start time, duration, frequency, sound pressure level, bandwidth, envelope measures, maximum ICI, minimum ICI and number of clicks are recorded [23]. These parameters are later be used by the KERNO automatic click train detection classifier in the CPOD.exe software (version 2.041, Chelonia Limited, Cornwall, UK) to determine whether a repetitive sequence of clicks (click train) corresponds to a cetacean that produces narrowband high frequency clicks ("NBHF") such as harbor porpoises, a cetacean that produces broadband click trains ("Other cet") such as bottlenose dolphins, or whether the clicks originate from a non-cetacean source such as a boat sonar [22,35]. At the locations used in this study, the NBHF class can be assumed to represent harbor porpoises, and the "Other cet" class can be assumed to correspond to bottlenose dolphin detections as other delphinids are relatively rare $[1,11]$.

Prior to deployment, field calibration trials on all C-PODs were carried out between November 2008 and March 2011 in Galway Bay and in the Shannon Estuary [11]. These trials incorporated all C-PODs used in the study as well as additional units, and all units were found to perform similarly, with less than $20 \%$ variation in the detection positive minutes detected between the devices [11].

At the conclusion of the monitoring period, C-PODs were retrieved and the data were extracted in the form of detection positive minutes (DPM) across hours, detection positive hours (DPH) across days, and click train characteristics using the accompanying CPOD.exe software version 2.041 [23,35]. The CPOD.exe species certainty filter was used to discard click trains with a low measure of species certainty, and only click trains with "high" inter-click interval assessment quality were retained in the analysis. Click trains with outlier ICI values longer than $450 \mathrm{~ms}$ for bottlenose dolphins and $250 \mathrm{~ms}$ for harbor porpoises were removed as per Nuuttila et al. [15]. Click trains were also visually inspected for false positives by examining the coherence of the click trains (even profile of the sound pressure level and appropriate frequency range) and the temporal association with other click trains $[35,36]$. Only hours with a complete, uninterrupted recording period of $60 \mathrm{~min}$ 
were retained in the analysis. The data from POD 1524 were not incorporated into the final analysis due to a recording malfunction which led to incomplete recording hours on six of the eight days during which it was deployed. The data from the Brandon Bay deployments were combined, as the deployments were consecutive.

\subsection{Environmental Data}

Each hour of the study period was categorized according to its phase of diel, tidal cycle, tidal phase, and month. These variables were selected as previous research has shown that diel phase, tidal cycle, tidal phase and season are significant, site-specific predictors of bottlenose dolphin presence and foraging within the Lower River Shannon SAC [6,11]. Sunset and sunrise times were obtained from www.timeanddate.com/sun/ (accessed on 10 January 2020) for the nearest available location, which was Tralee, Ireland. All sunrise and sunset times were rounded to the nearest hour and phases of the diel cycle ("Morning", "Day", Evening", "Night") were specified by assigning "Evening" and "Morning" to the three hour blocks consisting of the hour before, hour of and after sunrise (or sunset) and assigning the remaining hours between into their respective categories of "Day" and "Night". Tidal data were extracted using WXTide32 version 2.4 (http: / / www.wxtide32.com, accessed on 1 January 2020) [37] for Fenit Pier in Tralee Bay. The blocks of time consisting of the hour before, hour of, and hour after low and high slack tide were categorized as 'Low' and 'High' tidal cycles, respectively. 'Ebb' was defined as the period between 'High' and 'Low', and 'Flood' was defined as the period between 'Low' and 'High'. This classification follows the methodology described by $\mathrm{O}^{\prime}$ Brien et al. [11]. Tidal cycle measures short-term variability in tidal height and current speed over the lunar day, whereas tidal phase represents longer-term variation in tidal height over the course of the lunar month. The tidal phases were classified using the method described by O'Brien et al. [11] and O'Brien [38]. For each $24 \mathrm{~h}$ period, the high and low tides were subtracted from each other to calculate tidal variation. "Spring" tidal phase consisted of the three day period with the largest tidal variation $(24 \mathrm{~h}$ on either side of the $24 \mathrm{~h}$ period where tidal variation was maximal) and the "Neap" tidal phase consisted of the three day period with the lowest tidal variation. All tidal phases between "Spring" and "Neap" were assigned into a "Transitional" tidal phase category. In addition to the environmental variables, acoustic detections of harbor porpoises were also recorded to examine the relationship between harbor porpoise presence and dolphin presence at the study sites. Bottlenose dolphins are known to interact aggressively with harbor porpoises and previous research has shown temporal partitioning of habitat use by dolphin and harbor porpoises $[17,31,39]$.

\subsection{Statistical Modelling}

The study period was divided into $1 \mathrm{~h}$ time windows. The detection positive minutes per hour (DPM) were then used to create a binary presence/absence dataset, where dolphin presence was defined by there being at least 1 DPM within that hour. A foraging dataset was created following the methodology described by Wingfield et al. [40], by creating a subset of the presence/absence data consisting of only the hours during which there were detections and then categorizing each hour as " 1 " (foraging positive) if at least one click train with a minICI $<10 \mathrm{~ms}$ was recorded during that hour and " 0 " if no click trains were recorded with a minICI $<10 \mathrm{~ms}$ during that hour.

A binomial generalized linear model (GLM) with a logit link function was fitted in $R$ version 3.5.0 (R Foundation for Statistical Computing, Vienna, Austria) using the stats package to model the probability of presence and probability of foraging [41]. Diel phase, tidal cycle, tidal phase, month, and the presence of harbor porpoises were used as predictors in the dolphin presence models, and the predictors in the foraging models were diel phase, tidal cycle, tidal phase and month. Predictors were tested for collinearity by examining variance inflation factor (VIF) values using the corvif function in $R$ version 3.5.0 [41,42]. No collinearity was detected using a VIF cut-off value of 3 [42,43]. A hypothesis-testing approach was then employed for model selection where each explanatory variable was 
dropped from the model in turn, the difference in deviance of the models was calculated and compared to a Chi-square distribution, and the model was refitted without the nonsignificant term [43]. This process was repeated until all of the remaining explanatory variables were significant. Presence models were fitted separately for the Brandon Bay and the Maharees sites to determine the relative importance of predictors at each location. A foraging model was also fitted at the Brandon Bay location. There were insufficient detections to model foraging at the Maharees, and presence or foraging at the Ballyheigue Bay location.

Temporal autocorrelation may be present in timeseries data which would violate the model assumption that residuals are independent $[17,44]$. The patterns in the residuals were examined using an autocorrelation function (ACF) plot [17,44]. Nuuttila et al. [17] used a correlation threshold of 0.2 in the ACF plot to determine whether there was temporal autocorrelation in the presence and foraging models. In this study, the number of lags crossing the $95 \%$ confidence bounds and a correlation threshold of 0.2 were used to assess whether model residuals were temporally autocorrelated. For models where no autocorrelation was found, the GLM where all explanatory variables were significant was retained as the final model. However, when the ACF plot showed evidence of autocorrelation, a binomial GEE-GLM with a logit link function was fitted instead using the geepack package in R [41,45-47]. By adjusting for autocorrelation, GEE-GLMs yield more conservative results and are a valuable tool for modelling datasets where there is dependence between observations [43]. Julian date was selected as the blocking ID and an autoregressive (AR-1) correlation structure was chosen since the correlation between observations was time-dependent and decreased with increasing distance in time [43,44].

GEE-GLM model selection proceeded similarly to the GLM model selection, with a hypothesis-testing procedure where a Wald test was used to identify non-significant predictors and with each round of model selection, the non-significant predictors were removed and the model was refitted until all of the remaining predictors were significant [40]. Models with lower QIC values were preferred over those with a higher QIC value (MESS package in R) [39,48-50].

Model validation was carried out using confusion matrices, which compare the predicted values to the observed values and provide a measure of model sensitivity and specificity. A Receiver Operating Characteristic (ROC) curve was used to select the probability cut-off value, where the point of furthest distance between the ROC curve and the $45^{\circ}$ diagonal line was treated as the optimal probability value [48,51]. AUC was calculated using the PresenceAbsence package and also examined as an indicator of model performance, where the closer the value is to 1 , the better the model [52-54]. Finally, model predictions were plotted as boxplots on the scale of the response variable using the ggplot2 package in $\mathrm{R}[41,55]$.

\section{Results}

A total of $6963 \mathrm{~h}$ of acoustic data were collected across the three sites. Brandon Bay was the site with the highest cetacean activity, where dolphins were recorded on $92 \%$ of days and harbor porpoises on $89 \%$ of days. Of the $3382 \mathrm{~h}$ recorded at Brandon Bay, there were 1101 detection positive hours (DPH) for dolphins and $480 \mathrm{DPH}$ for harbor porpoises. At the Maharees, where $2741 \mathrm{~h}$ were recorded, there were $34 \mathrm{DPH}$ for dolphins and 431 $\mathrm{DPH}$ for harbor porpoises. Ballyheigue Bay was the site with the least cetacean activity. Of the $840 \mathrm{~h}$ recorded, there were only $2 \mathrm{~h}$ with dolphin detections and $25 \mathrm{~h}$ with harbor porpoise detections.

\subsection{Presence}

The best model for dolphin presence in Brandon Bay was a binomial GEE-GLM which retained month $(p<0.001)$, tidal cycle $(p<0.01)$ and the presence of harbor porpoises $(p<0.001)$ as significant predictors (Table 2$)$. Model validation indicated good performance with an AUC of 0.71 (see Supplementary Materials). 
Table 2. Binomial GEE-GLM output (Dolphin presence in Brandon Bay). The output shows the estimate, standard error, Wald test statistic, and $p$-values for each predictor. Significant predictors are highlighted in bold.

\begin{tabular}{|c|c|c|c|c|c|}
\hline Model Variable & Estimate & Standard Error & Wald & $P(>|W|)$ & Significance Level \\
\hline Intercept & 0.0341 & 0.1736 & 0.04 & 0.8443 & \\
\hline \multicolumn{6}{|l|}{ Tidal cycle (relative to Ebb) } \\
\hline Flood & -0.3904 & 0.1227 & 10.12 & 0.0015 & $<0.01$ \\
\hline High & -0.0274 & 0.1043 & 0.07 & 0.7926 & \\
\hline Low & -0.0250 & 0.1168 & 0.05 & 0.8303 & \\
\hline \multicolumn{6}{|l|}{ Month (relative to August) } \\
\hline May & -2.3062 & 0.3723 & 38.37 & $5.8 \times 10^{-10}$ & $<0.001$ \\
\hline June & -1.9648 & 0.2572 & 58.36 & $2.2 \times 10^{-14}$ & $<0.001$ \\
\hline July & -0.5116 & 0.1992 & 6.60 & 0.0102 & $<0.05$ \\
\hline September & -0.2076 & 0.2269 & 0.84 & 0.3603 & \\
\hline October & -0.3378 & 0.2474 & 1.86 & 0.1721 & \\
\hline Harbor porpoise presence & -0.5964 & 0.1080 & 30.52 & $3.3 \times 10^{-8}$ & $<0.001$ \\
\hline
\end{tabular}

Figure 2 shows that the probability of dolphin presence was lowest at the Brandon Bay site in May and June, and increased steeply throughout the summer, with a peak probability of 0.5 in August. The probability of dolphin presence then showed a gradual decreasing trend during September and October. There was a lower probability of occurrence of dolphins during flood tides $(p<0.01)$ compared to all other phases of the tidal cycle and the presence of harbor porpoises significantly reduced the predicted occurrence of dolphins $(p<0.001)$.
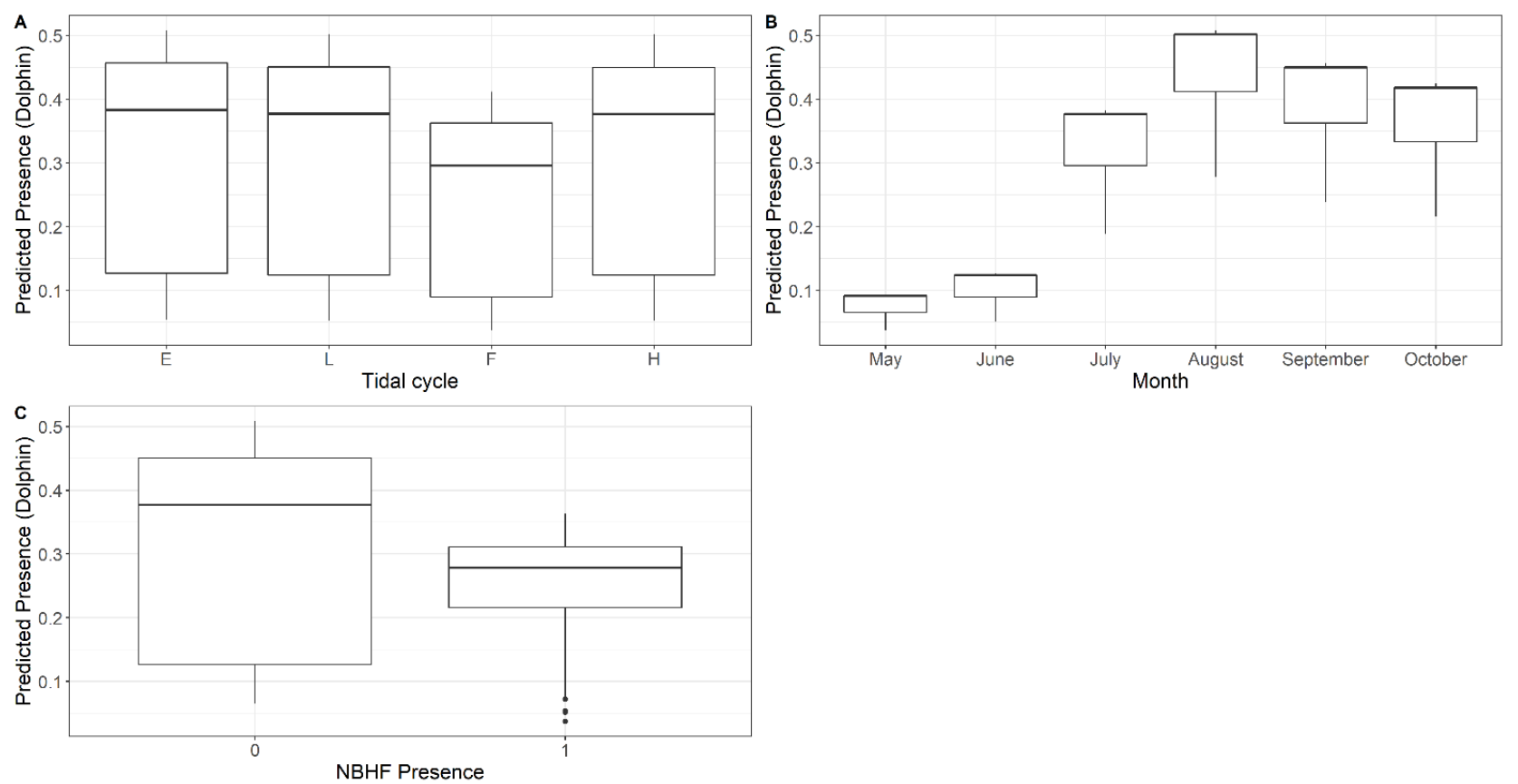

Figure 2. The predicted probability of bottlenose dolphin presence at Brandon Bay according to: (A) tidal cycle, where " $\mathrm{E}^{\prime \prime}=$ ebb tide, " $\mathrm{L}$ " = low tide, " $\mathrm{F}$ " = flood tide, and " $\mathrm{H}$ " = high tide; (B) month, from May to October; (C) harbor porpoise $(\mathrm{NBHF})$ presence, where " 0 " represents the absence of harbor porpoises, and " 1 " represents harbor porpoise presence.

In contrast to Brandon Bay, tidal cycle and the presence of harbor porpoises had no significant effect on the probability of dolphin occurrence at the Maharees. The final model for dolphin presence at the Maharees was a binomial GLM, which retained diel phase $(p<0.001)$ and month $(p<0.05)$ as significant predictors (Table 3). 
Table 3. Binomial GLM output (dolphin presence at the Maharees). The output shows the estimate, standard error, $z$ value and $p$-values for each predictor. Significant predictors are highlighted in bold.

\begin{tabular}{|c|c|c|c|c|c|}
\hline Model Variable & Estimate & Standard Error & Z Value & $P(>|z|)$ & Significance Level \\
\hline Intercept & -6.5603 & 1.0175 & -6.447 & $1.14 \times 10^{-10}$ & \\
\hline \multicolumn{6}{|c|}{ Diel Phase (relative to Day) } \\
\hline Evening & 2.5864 & 1.1207 & 2.308 & 0.021005 & $<0.05$ \\
\hline Night & 3.5974 & 1.0213 & 3.522 & 0.000428 & $<0.001$ \\
\hline Morning & -13.5065 & 942.3163 & -0.014 & 0.988564 & \\
\hline \multicolumn{6}{|c|}{ Month (relative to August) } \\
\hline July & -1.1209 & 1.0496 & -1.068 & 0.285539 & \\
\hline September & -0.9022 & 0.5074 & -1.778 & 0.075397 & \\
\hline October & -0.2542 & 0.4032 & -0.631 & 0.528335 & \\
\hline November & -2.1693 & 1.0464 & -2.073 & 0.038160 & $<0.05$ \\
\hline
\end{tabular}

The AUC of this model was 0.83 , indicating good performance. The model predicted significantly higher dolphin presence at night $(p<0.001$, Figure 3$)$. The predicted probability of dolphin presence at night was approximately 0.04 , while the predicted probability approached 0 during the morning and day, with an intermediate probability of dolphin presence in the evening. There was also a significantly lower probability of dolphins being present at the Maharees during the month of November relative to August $(p<0.05$, Figure 3).
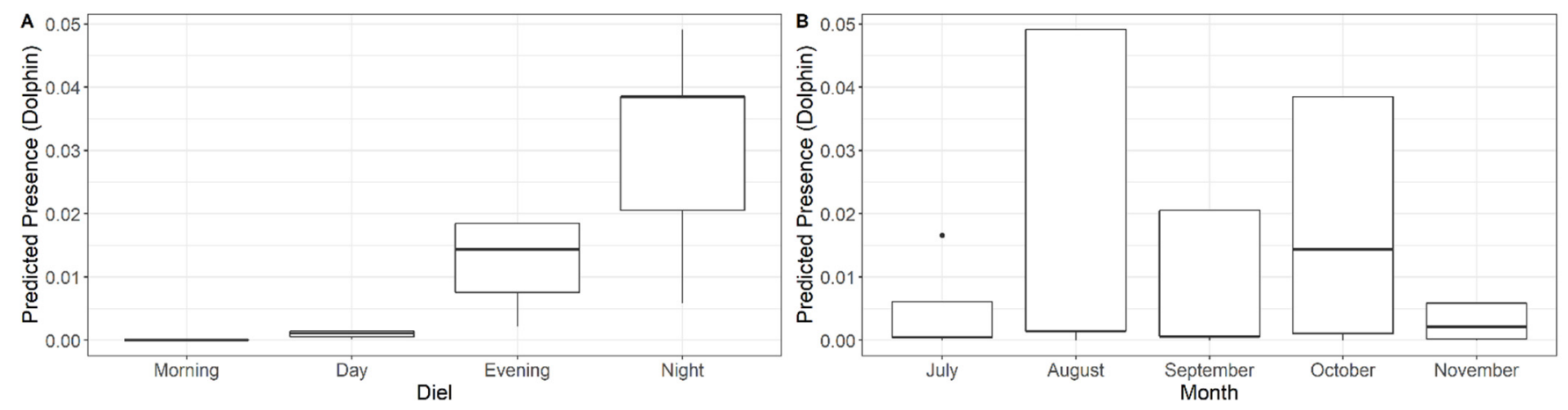

Figure 3. The predicted probability of bottlenose dolphin presence at the Maharees according to: (A) the time of day, where the four categories of diel phase are "Morning", "Day", "Evening", and "Night"; (B) month, from July to November.

\subsection{Foraging}

Overall, $29 \%$ of dolphin click trains and $31 \%$ of harbor porpoise click trains were positive for foraging activity. The site with the highest percentage of foraging positive hours for both dolphins and harbor porpoises was Brandon Bay, where foraging by dolphins occurred in $20 \%$ of all monitored hours and by harbor porpoises in $31 \%$ of all monitored hours. In contrast, at the Maharees dolphins foraged on only $0.5 \%$ of hours monitored and harbor porpoises on $5.7 \%$ of all hours. When dolphins, or harbor porpoises, were present at either site, at least one third of their time was spent foraging. At Brandon Bay, dolphins foraged during $64 \%$ of the time they were present and harbor porpoises $42 \%$ of the time. At the Maharees, dolphins foraged $54 \%$ of the time they were present and harbor porpoises $32 \%$ of the time. Cetacean presence at Ballyheigue Bay was too low to assess foraging trends.

At the Brandon Bay site, there was no temporal autocorrelation in the foraging model residuals. A binomial GLM with an AUC of 0.65 was retained as the best foraging model for bottlenose dolphins (Table 4). 
Table 4. Binomial GLM output (Foraging Positive Hour (FPH)-based analysis of dolphin foraging in Brandon Bay). The output shows the estimate, standard error, $\mathrm{z}$ value and $p$-values for each predictor. Significant predictors are highlighted in bold.

\begin{tabular}{|c|c|c|c|c|c|}
\hline Model Variable & Estimate & Standard Error & z Value & $P(>|z|)$ & Significance Level \\
\hline Intercept & 1.0011 & 0.1368 & 7.318 & $2.51 \times 10^{-13}$ & \\
\hline \multicolumn{6}{|c|}{ Diel Phase (relative to Day) } \\
\hline Evening & -0.1682 & 0.2079 & -0.809 & 0.418587 & \\
\hline Night & -0.6258 & 0.1646 & -3.801 & 0.000144 & $<0.001$ \\
\hline Morning & -0.0197 & 0.2161 & -0.091 & 0.927355 & \\
\hline \multicolumn{6}{|c|}{ Month (relative to August) } \\
\hline May & -0.9231 & 0.6478 & -1.425 & 0.154189 & \\
\hline June & -1.0812 & 0.2554 & -4.233 & $2.30 \times 10^{-5}$ & $<0.001$ \\
\hline July & -0.8472 & 0.1782 & -4.755 & $1.98 \times 10^{-6}$ & $<0.001$ \\
\hline September & 0.2384 & 0.1829 & 1.304 & 0.192357 & \\
\hline October & -0.1918 & 0.2460 & -0.780 & 0.435391 & \\
\hline
\end{tabular}

The significant predictors of foraging during periods of dolphin presence in Brandon Bay were diel phase $(p<0.01)$ and month $(p<0.001)$. Foraging probability was significantly lower for the months of June and July relative to the August-September peak. Figure 4 shows that the probability of dolphin foraging was approximately 0.5 from May to July and increased to a peak of approximately 0.7 in August to September, remaining high in October. Foraging probability was also significantly lower for dolphins present in Brandon Bay at night compared to all other times (Figure $4, p<0.001$ ). It was not possible to model the trends in foraging probability at the Maharees site, since dolphins were only present during $1 \%$ of monitored hours.
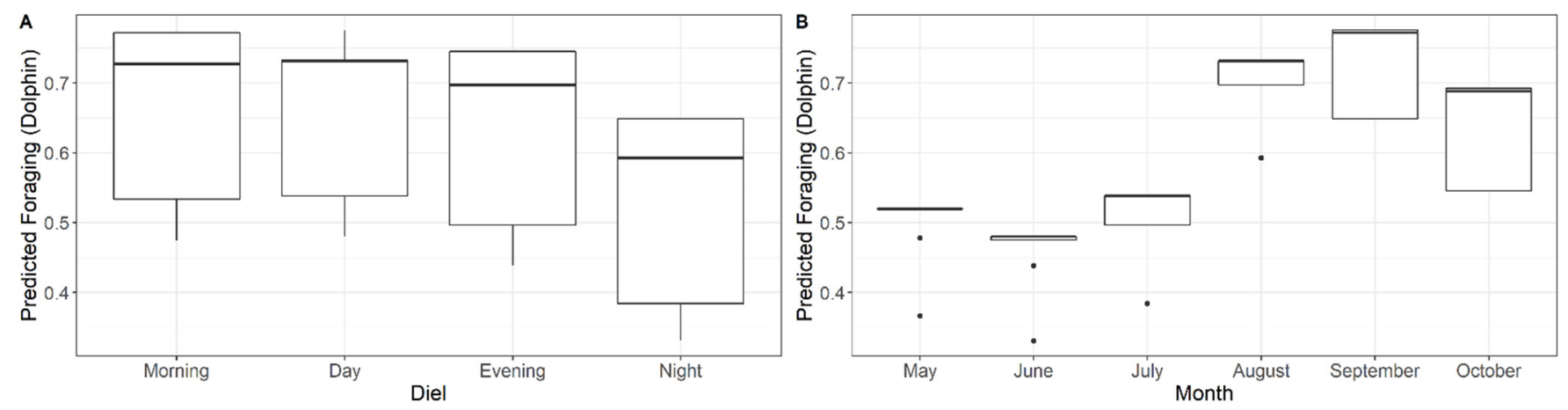

Figure 4. FPH-based binomial GLM. The predicted probability of dolphin foraging at Brandon Bay according to: (A) the time of day, where the four categories of diel phase are "Morning", "Day", "Evening", and "Night"; (B) Month, from May to October. Predicted foraging is measured by the proportion of foraging positive hours, which are hours containing at least one click train with a minICI $<10 \mathrm{~ms}$.

\section{Discussion}

This is the first acoustic monitoring study to explore the use of habitats beyond the limits of the Lower River Shannon SAC by bottlenose dolphins from the Shannon Estuary population. Although the boundaries of marine protected areas (and SACs) are typically fixed, bottlenose dolphins are highly mobile, wide ranging, and can have seasonal shifts in their distribution $[16,21,56]$. The Moray Firth is an example of a SAC that was established to protect the core area of a resident population of bottlenose dolphins in Scotland [21]. Over the years, the number of bottlenose dolphin sightings outside of the Moray Firth SAC increased, and in 2019, Arso Civil et al. [21] published evidence of range expansion by these dolphins and a marked change in distribution with sites of importance for the population up to $300 \mathrm{~km}$ to the south of the Moray Firth SAC. Fernandez-Betelu et al. [16] recommended a more dynamic approach to MPA management taking into account temporal variation in cetacean movements. As a result, it is necessary not only to carry out long-term monitoring 
of populations within a SAC, but also to monitor sightings and trends in foraging at adjacent locations beyond the boundaries of the SAC.

The results of this study show that there was consistent bottlenose dolphin presence and foraging activity in Brandon Bay, where dolphins were present on $92 \%$ of days monitored and with foraging occurring on $20 \%$ of all hours monitored. These levels of presence and foraging are comparable to those reported by Carmen et al. [6] within the Shannon Estuary, where the number of days with detections ranged from $15.9 \%$ at the site with the least detections to $71.2 \%$ of days monitored at Moneypoint, with the highest number of detections. The foraging rates within the Shannon Estuary increased with increasing distance upriver from the mouth of the estuary in the Carmen et al. [6] study, with foraging click trains making up $7.3 \%$ of all click trains at the Moneypoint location and $21.9 \%$ of click trains at the upriver Shannon Airport location.

The Maharees location, between the Brandon Bay and Ballyheigue Bay sites, had much lower dolphin presence than Brandon Bay, with dolphins occurring on $25 \%$ of days monitored. Ballyheigue Bay, which was the site closest to the Lower River Shannon SAC (Figure 1), had the lowest dolphin presence, with dolphins occurring on only $6 \%$ of days monitored. However, the duration of the monitoring period was shorter at Ballyheigue Bay (34 days) than at Brandon Bay (140 days) and the Maharees (113 days), and monitoring at Ballyheigue Bay took place only during May and June, which were also the months with the lowest dolphin presence at Brandon Bay. Therefore, to understand whether these data truly reflect very little dolphin occurrence at Ballyheigue Bay or whether the low occurrence is only a reflection of the time of the year during which the recording took place, monitoring at Ballyheigue Bay should be repeated for a longer period of time and should include the late summer and autumn months.

The environmental variables that predicted bottlenose dolphin presence and foraging at Brandon Bay and at the Maharees were tidal cycle, month, diel phase and the presence of harbor porpoises. The specific combination of predictors varied by site and depended on whether foraging or presence was the outcome of interest. In Brandon Bay, tidal cycle and month were significant predictors of presence. O'Brien et al. [11] also found tidal cycle to be a significant predictor of presence within the Shannon Estuary, with a site-specific response pattern at different sites within the estuary. Carmen et al. [6] found tidal cycle, tidal phase, diel phase, and season were all significant predictors of foraging within the Shannon Estuary, with the exception of the innermost site at Shannon Airport where foraging was only influenced by tidal variables.

Our findings were consistent with previous research that has found marked, sitespecific variation in the contribution of tidal variables to dolphin presence and foraging [16,18]. Fernandez-Betelu et al. [16] analyzed bottlenose dolphin responses to tidal cycle at three sites within the Moray Firth SAC, Scotland and found that tidal cycle had a significant effect on dolphin presence at the Chanonry site within the SAC, which is a narrow channel with a strong tidal flow. However, there was no effect of tidal cycle at the Spey Bay site, which is the most open location. The highly site-specific response to tidal cycle may depend on the way tidal flow interacts with the specific hydrographic and bathymetric features of each location at a fine scale $[16,18]$. At the Maharees site, tidal cycle was dropped as a predictor of dolphin presence and instead month and diel phase were significant predictors of dolphin presence, which were the variables that predicted bottlenose dolphin foraging in Brandon Bay. However, there were so few detections of dolphins at the Maharees that the significance of these predictors should be interpreted with caution.

The months with the highest bottlenose dolphin presence in Brandon Bay were August and September, with foraging peaking in September. At the Maharees, dolphin presence was at its highest in August. Pirotta et al. [18] identified a peak in bottlenose foraging during the summer and autumn months, and attributed this peak to the migratory return of salmon (Salmo salar) to the Moray Firth SAC in Scotland. Salmonids in general are known to be an important prey species of bottlenose dolphins, and in the Shannon Estuary, 
bottlenose dolphins have been observed tossing salmon out of the water during foraging attempts [8,21,57]. Ingram and Rogan [8] proposed that the presence of salmon may explain the use of the estuary by bottlenose dolphins. To understand the significance of season on bottlenose dolphin presence and foraging and how this is influenced by prey dynamics in locations beyond the boundaries of the Lower River Shannon SAC, it will be necessary to carry out longer-term, year round acoustic monitoring similar to the work carried out within the estuary by Carmen et al. [6].

Dolphin presence was significantly lower in Brandon Bay during periods of harbor porpoise presence. Previous research has shown that when bottlenose dolphins and harbor porpoises utilize the same habitat, their occurrence tends to be temporally partitioned. For example, Todd et al. [39] found a negative temporal correlation between harbor porpoise and bottlenose dolphin detections at Broadhaven Bay in Northern Ireland, and Nuuttila et al. [17] demonstrated three types of temporal partitioning between bottlenose dolphins and porpoises: seasonal, diel, and tidal. It is possible that partitioning occurs to reduce competition for prey and minimize the risk of aggressive encounters. The diet of harbor porpoises and bottlenose dolphins has considerable overlap, with fish such as gadoids and Trisopterus species making up the majority of the diet for bottlenose dolphins and harbor porpoises in Irish waters [57-59]. Aggression is known to occur between dolphins and harbor porpoises, and post-mortem analyses of stranded porpoises in Wales and Scotland have revealed that attack by bottlenose dolphin is a common cause of death $[31,60]$. Competition for prey is a possible explanation for the aggression since dolphins and porpoises share common resources. The finding that dolphin presence was lower in Brandon Bay when harbor porpoises were present, or conversely that harbor porpoises tended to be present when dolphins were absent, is in line with previous research demonstrating temporal partitioning between bottlenose dolphins and harbor porpoises.

The fine-scale variation and high site specificity of environmental predictors observed in this study and in previous studies within the Lower River Shannon SAC highlight the importance of localized management actions [6,11]. For example, mitigating impact on the Shannon bottlenose dolphin population within the Lower River Shannon SAC could involve a reduction in evening-time industrial activity since Carmen et al. [6] found that this was a particularly important period for foraging at Moneypoint and Foynes. In contrast, the results of our study show that at Brandon Bay, foraging was higher in the morning and during the day, so a different approach would be recommended there. The long-term datasets obtained through static acoustic monitoring can be utilized to decide whether certain activities should be allowed or prohibited in certain locations, and whether scheduling activities during certain tidal cycles, tidal phases, times of day or times of the year could minimize risk.

In 2016, Levesque et al. [1] proposed expanding the boundary of the Lower River Shannon SAC to include Brandon Bay. Given that dolphins were observed on $90 \%$ of Levesque et al.'s [1] surveys in Brandon and Tralee Bays and that $96 \%$ of these dolphins were matched to the Shannon Estuary population, it is likely that the majority of dolphins encountered in Brandon and Tralee Bays belong to the Shannon population. The results of this study further support the importance of the Brandon Bay site, since dolphins were detected there at comparable rates to within the Shannon Estuary. Acoustic detections occurred on $92 \%$ of the days monitored at Brandon Bay and foraging occurred on $20 \%$ of all hours monitored. Our study supports the recommendation that the boundaries of the Lower River Shannon SAC should be adjusted to incorporate Brandon Bay. Because Brandon Bay is less impacted by anthropogenic activity than the Shannon Estuary, protecting this foraging hotspot for Shannon dolphins could ensure that some relatively undisturbed habitat remains available to the population.

Supplementary Materials: The following are available online at https://www.mdpi.com/article/10 .3390/jmse9060650/s1, Figure S1: ROC plot for the final Brandon Bay Dolphin Presence GEE-GLM; Figure S2: ROC plot for the final Maharees Dolphin Presence GLM; Figure S3: ROC plot for the final Brandon Bay Dolphin Foraging GLM; Figure S4: ACF plot for the Brandon Bay Dolphin Presence 
GLM indicating autocorrelation and the need for a GEE-GLM modelling approach; Figure S5: ACF plot for the Maharees Dolphin Presence GLM where no autocorrelation was detected, as few lags cross the $95 \%$ confidence bounds and the magnitude of the correlation threshold is below 0.2; Figure S6: ACF plot for the Brandon Bay Dolphin Foraging GLM where no autocorrelation was detected, as few lags cross the $95 \%$ confidence bounds and the magnitude of the correlation threshold is below 0.2.

Author Contributions: Conceptualization, J.O. and S.B.; methodology, J.O. and R.C.; software, R.C.; validation, J.O. and R.C.; formal analysis, R.C.; investigation, R.C. and J.O.; resources, S.B. and J.O.; data curation, R.C. and J.O.; writing-original draft preparation, R.C.; writing-review and editing, All; visualization, R.C.; supervision, J.O.; project administration, S.B. and J.O.; funding acquisition, S.B. and J.O. All authors have read and agreed to the published version of the manuscript.

Funding: This research was funded by the Rural Development Programme (LEADER), North, East and West Kerry Development (NEWKD) and the Erasmus Mundus Joint Master scholarship.

Institutional Review Board Statement: Not applicable.

Informed Consent Statement: Not applicable.

Data Availability Statement: The data presented in this study are available on request from the corresponding author. The data are not publicly available, as it is owned by various organizations.

Acknowledgments: We would like to thank John A. Moriarty of North East Kerry Development for his support throughout, the LEADER programme for funding C-POD deployments and recovery, John B. Moriarty, Michael Moriarty, Finbarr O'Connell, and Michael Beakes.

Conflicts of Interest: The authors declare no conflict of interest.

\section{References}

1. Levesque, S.; Reusch, K.; Baker, I.; O’Brien, J.; Berrow, S. Photo-identification of bottlenose dolphins (Tursiops truncatus) in Tralee and Brandon Bay, Co. Kerry: A case for SAC boundary extension. Biol. Environ. 2016, 116B, 109-118. [CrossRef]

2. Mirimin, L.; Miller, R.; Dillane, E.; Berrow, S.D.; Ingram, S.; Cross, T.F.; Rogan, E. Fine-scale population genetic structuring of bottlenose dolphins in Irish coastal waters. Anim. Conserv. 2011, 14, 342-353. [CrossRef]

3. Blázquez, M.; Baker, I.; O’Brien, J.M.; Berrow, S.D. Population viability analysis and comparison of two monitoring strategies for bottlenose dolphins (Tursiops truncatus) in the Shannon Estuary (Ireland) to inform management. Aquat. Mamm. 2020, 46, 307-325. [CrossRef]

4. Louis, M.; Viricel, A.; Lucas, T.; Peltier, H.; Alfonsi, E.; Berrow, S.; Brownlow, A.; Covelo, P.; Dabin, W.; Deaville, R.; et al. Habitat-driven population structure of bottlenose dolphins, Tursiops truncatus, in the North-East Atlantic. Mol. Ecol. 2014, 23, 857-874. [CrossRef]

5. Berrow, S.D.; Holmes, B.; Kiely, O.R. Distribution and abundance of bottle-nosed dolphins Tursiops truncatus (Montagu) in the Shannon Estuary. Biol. Environ. 1996, 96B, 1-9.

6. Carmen, M.; Berrow, S.D.; O’Brien, J.M. Foraging behavior of bottlenose dolphins in the Shannon Estuary, Ireland as determined through static acoustic monitoring. J. Mar. Sci. Eng. 2021, 9, 275. [CrossRef]

7. Knott, M.J. Two Months in Kilkee, 2nd ed.; Clasp Press: Ennis, Ireland, 1997; p. 255.

8. Ingram, S.N.; Rogan, E. Identifying critical areas and habitat preferences of bottlenose dolphins Tursiops truncatus. Mar. Ecol. Prog. Ser. 2002, 244, 247-255. [CrossRef]

9. Barker, J.; Berrow, S. Temporal and spatial variation in group size of bottlenose dolphins (Tursiops truncatus) in the Shannon Estuary, Ireland. Biol. Environ. 2016, 116B, 63-70. [CrossRef]

10. SIFP. Strategic Integrated Framework Plan for the Shannon Estuary. 2013. Available online: http://www.shannonestuarysifp.ie (accessed on 26 February 2021).

11. O'Brien, J.; Beck, S.; Wall, D.; Pierini, A.; Hanbsen, S. Marine Mammals and Megafauna in Irish Waters-Behavior, Distribution and Habitat Use: Work Package 2: Developing Acoustic Monitoring Techniques; PReCAST Final Report; Marine Research Sub-Programme 2007-2013; Marine Institute: Oranmore, Ireland, 2013; pp. 76, 86.

12. Ingram, S.N.; Englund, A.; Rogan, E. An Extensive Survey of Bottlenose Dolphins (Tursiops truncatus) on the West Coast of Ireland; Heritage Council Report No. WLD/2001/42; University College Cork: Cork, Ireland, 2001; pp. 1-17.

13. Ryan, C.; Berrow, S. An extension to the known home range of Shannon Estuary bottlenose dolphins (Tursiops truncatus (Montagu, 1821)). Ir. Nat. J. 2013, 32, 77-78.

14. Berrow, S.D.; O’Brien, J.; Meade, R.; Delarue, J.; Kowarski, K.; Martin, B.; Moloney, J.; Wall, D.; Gillespie, D.; Leaper, R.; et al. Acoustic Surveys of Cetaceans in the Irish Atlantic Margin in 2015-2016: Occurrence, Distribution and Abundance; Department of Communications, Climate Action \& Environment and the National Parks and Wildlife Service (NPWS), Department of Culture, Heritage and the Gaeltacht: Dublin, Ireland, 2018; p. 283. 
15. Nuuttila, H.K.; Meier, R.; Evans, P.G.H.; Turner, J.R.; Bennell, J.D.; Hiddink, J.G. Identifying foraging behaviour of wild bottlenose dolphins (Tursiops truncatus) and harbour porpoises (Phocoena phocoena) with static acoustic dataloggers. Aquat. Mamm. 2013, 39, 147-161. [CrossRef]

16. Fernandez-Betelu, O.; Graham, I.M.; Cornulier, T.; Thompson, P.M. Fine scale spatial variability in the influence of environmental cycles on the occurrence of dolphins at coastal sites. Sci. Rep. 2019, 9, 2548. [CrossRef]

17. Nuuttila, H.K.; Courtene-Jones, W.; Baulch, S.; Simon, M.; Evans, P.G.H. Don't forget the porpoise: Acoustic monitoring reveals fine-scaled temporal variation between bottlenose dolphin and harbour porpoise in Cardigan Bay SAC. Mar. Biol. 2017, 164, 50. [CrossRef]

18. Pirotta, E.; Thompson, P.M.; Miller, P.I.; Brookes, K.L.; Cheney, B.; Barton, T.R.; Graham, I.M.; Lusseau, D. Scale-dependent foraging ecology of a marine top predator modelled using passive acoustic data. Funct. Ecol. 2014, 28, 206-217. [CrossRef]

19. Guisan, A.; Zimmermann, N.E. Predictive habitat distribution models in ecology. Ecol. Modell. 2000, 135, 147-186. [CrossRef]

20. Redfern, J.V.; Ferguson, M.C.; Becker, E.A.; Hyrenbach, K.D.; Good, C.; Barlow, J.; Kaschner, K.; Baumgartner, M.F.; Forney, K.A.; Balance, L.T.; et al. Techniques for cetacean-habitat modeling. Mar. Ecol. Prog. Ser. 2006, 310, 271-295. [CrossRef]

21. Arso Civil, M.; Quick, N.J.; Cheney, B.; Pirotta, E.; Thompson, P.M.; Hammond, P.S. Changing distribution of the east coast of Scotland bottlenose dolphin population and the challenges of area-based management. Aquat. Conserv. 2019, 29, 178-196. [CrossRef]

22. Chelonia Limited. C-POD User Guide. Available online: https://www.chelonia.co.uk/downloads/C-POD\%20User\%20Guide\% 20BPC4\%20up\%20to\%20POD2089.pdf (accessed on 1 January 2020).

23. Chelonia Limited. CPOD (Version 2.041). Available online: www.chelonia.co.uk (accessed on 5 January 2020).

24. Caldwell, M.C.; Caldwell, D.K.; Tyack, P.L. Review of the signature-whistle hypothesis for the Atlantic bottlenose dolphin. In The Bottlenose Dolphin; Leatherwood, S., Reeves, R.R., Eds.; Academic Press: San Diego, CA, USA, 1990; pp. $199-234$.

25. Tyack, P.L. Studying How Cetaceans Use Sound to Explore Their Environment. In Perspectives in Ethology; Owings, D., Beecher, M.D., Thompson, N.S., Eds.; Plenum Press: New York, NY, USA, 1997; Volume 12, pp. 251-297.

26. Janik, V.M. Acoustic Communication in Delphinids. In Advances in the STUDY of behavior; Naguib, M., Janik, V.M., Eds.; Academic Press: Burlington, VT, USA, 2009; Volume 40, pp. 123-157. [CrossRef]

27. Tyack, P.L. Functional aspects of cetacean communication. In Cetacean Societies: Field Studies of Dolphins and Whales, 1st ed.; Mann, J., Connor, R.C., Tyack, P.L., Whitehead, H., Eds.; University of Chicago Press: Chicago, IL, USA, $2000 ;$ pp. $270-307$.

28. Wahlberg, M.; Jensen, F.H.; Soto, N.A.; Beedholm, K.; Bejder, L.; Oliveira, C.; Rasmussen, M.; Simon, M.; Villadsgaard, A.; Madsen, P.T. Source parameters of echolocation clicks from wild bottlenose dolphins (Tursiops aduncus and Tursiops truncatus). J. Acoust. Soc. Am. 2011, 130, 2263-2274. [CrossRef] [PubMed]

29. Clausen, K.T.; Wahlberg, M.; Beedholm, K.; Deruiter, S.; Madsen, P.T. Click communication in harbour porpoises Phocoena Phocoena. Bioacoustics 2011, 20, 1-28. [CrossRef]

30. Miller, L.A. Prey capture by harbor porpoises (Phocoena phocoena): A comparison between echolocators in the field and in captivity. J. Acoust. Soc. Jpn. 2010, 37, 156-168.

31. Simon, M.; Nuuttila, H.; Reyes-Zamudio, M.M.; Ugarte, F.; Verfub, U.; Evans, P.G.H. Passive acoustic monitoring of bottlenose dolphin and harbour porpoise, in Cardigan Bay, Wales, with implications for habitat use and partitioning. J. Mar. Biol. Assoc. U.K. 2010, 90, 1539-1545. [CrossRef]

32. Koschinski, S.; Diederichs, A.; Amundin, M. Click train patterns of free-ranging harbour porpoises acquired using T-PODs may be useful as indicators of their behaviour. J. Cetacean Res. Manag. 2008, 10, 147-155.

33. Akamatsu, T.; Wang, D.; Wang, K.; Naito, Y. Biosonar behaviour of free-ranging porpoises. Proc. R. Soc. B 2005, $272,797-801$. [CrossRef]

34. Villadsgaard, A.; Wahlberg, M.; Tougaard, J. Echolocation signals of wild harbour porpoises, Phocoena phocoena. J. Exp. Biol. 2007, 210, 56-64. [CrossRef]

35. Chelonia Limited. CPOD.exe: A Guide for Users. Available online: https://www.chelonia.co.uk/downloads/CPOD.pdf (accessed on 5 January 2020).

36. Chelonia Limited. Validating Cetacean Detections. Available online: https://www.chelonia.co.uk/downloads/Validating\%20 cetacean\%20detections.pdf (accessed on 15 January 2020).

37. WXTide 32 (Version 2.4). Available online: http:/ / www.wxtide32.com (accessed on 1 January 2020).

38. O'Brien, J. The Inshore Distribution and Abundance of Small Cetaceans on the West Coast of Ireland: Site Assessment for SAC Designation and an Evaluation of Monitoring Techniques. Ph.D. Thesis, Galway-Mayo Institute of Technology, Galway, Ireland, 2009.

39. Todd, N.R.E.; Cronin, M.; Luck, C.; Bennison, A.; Jessopp, M.; Kavanagh, A.S. Using passive acoustic monitoring to investigate the occurrence of cetaceans in a protected marine area in northwest Ireland. Estuar. Coast. Shelf Sci. 2020, 232, 106509. [CrossRef]

40. Wingfield, J.E.; O’Brien, M.; Lyubchich, V.; Roberts, J.J.; Halpin, P.N.; Rice, A.N.; Bailey, H. Year-round spatiotemporal distribution of harbour porpoises within and around the Maryland wind energy area. PLoS ONE 2017, 12, e0176653. [CrossRef] [PubMed]

41. R Core Team. R: A Language and Environment for Statistical Computing; R Foundation for Statistical Computing: Vienna, Austria. Available online: https:/ / www.R-project.org/ (accessed on 1 January 2020).

42. Zuur, A.F.; Hilbe, J.M.; Ieno, E.N. A Beginner's Guide to GLM and GLMM with R. A Frequentist and Bayesian Perspective for Ecologists, 1st ed.; Highland Statistics Ltd.: Newburgh, UK, 2013; pp. 52-54. 
43. Zuur, A.F.; Ieno, E.N.; Walker, N.J.; Saveliev, A.A.; Smith, G.M. Mixed Effects Models and Extensions in Ecology with R, 1st ed.; Springer: New York, NY, USA, 2009; pp. 295-320, 387. [CrossRef]

44. Bailey, H.; Corkrey, R.; Cheney, B.; Thompson, P.M. Analyzing temporally correlated dolphin sightings data using generalized estimating equations. Mar. Mamm. Sci. 2013, 29, 123-141. [CrossRef]

45. Højsgaard, S.; Halekoh, U.; Yan, J. The R package geepack for generalized estimating equations. J. Stat. Softw. 2006, 15, 1-11. [CrossRef]

46. Yan, J. geepack: Yet another package for generalized estimating equations. $R$ News 2002, 2, 12-14.

47. Yan, J.; Fine, J.P. Estimating equations for association structures. Stat. Med. 2004, 23, 859-880. [CrossRef] [PubMed]

48. Pirotta, E.; Matthiopolous, J.; MacKenzie, M.; Scott-Hayward, L.; Rendell, L. Modelling sperm whale habitat preference: A novel approach combining transect and follow data. Mar. Ecol. Prog. Ser. 2011, 436, 257-272. [CrossRef]

49. Ekstrøm, C.T. MESS: Miscellaneous Esoteric Statistical Scripts. R Package Version 0.5.6. Available online: https://CRAN.Rproject-org / package=MESS (accessed on 1 February 2020).

50. Pan, W. Aikake's information criterion in generalized estimating equations. Biometrics 2001, 57, 120-125. [CrossRef] [PubMed]

51. Zweig, M.H.; Campbell, G. Receiver-operating characteristic (ROC) plots: A fundamental evaluation tool in clinical medicine. Clin. Chem. 1993, 39, 561-577. [CrossRef]

52. Boyce, M.S.; Vernier, P.R.; Nielsen, S.E.; Schmiegelow, F.K.A. Evaluating resource selection functions. Ecol. Modell. 2002, 157, 281-300. [CrossRef]

53. Cumming, G.S. Using between-model comparisons to fine-tune linear models of species ranges. J. Biogeogr. 2000, 27, 441-455. [CrossRef]

54. Freeman, E.A.; Moisen, G. PresenceAbsence: An R package for presence absence analysis. J. Stat. Softw. 2008, 23, 1-31. [CrossRef]

55. Wickham, H. ggplot2 Elegant Graphics for Data Analysis, 2nd ed.; Springer: New York, NY, USA, 2016; pp. 1-7.

56. Wilson, B.; Reid, R.J.; Grellier, K.; Thompson, P.M.; Hammond, P.S. Considering the temporal when managing the spatial: A population range expansion impacts protected areas-based management for bottlenose dolphins. Anim. Conserv. 2004, 7, 331-338. [CrossRef]

57. Santos, M.; Pierce, G.; Reid, R.; Patterson, I.; Ross, H.; Mente, E. Stomach contents of bottlenose dolphins (Tursiops truncatus) in Scottish waters. J. Mar. Biolog. Assoc. U.K. 2001, 81, 873-878. [CrossRef]

58. Hernandez-Milian, G.; Berrow, S.; Begoña Santos, M.; Reid, D.; Rogan, E. Insights into the trophic ecology of bottlenose dolphins (Tursiops truncatus) in Irish waters. Aquat. Mamm. 2015, 41, 226-239. [CrossRef]

59. Rogan, E.; Berrow, S. Review of Harbour Porpoises Phocoena Phocoena, L. in Irish Waters; Report of the International Whaling Commission 46; University College Cork: Cork, Ireland, 1996; pp. 595-605.

60. Penrose, R. Marine Mammal and Marine Turtle Strandings. Welsh Coast, Annual Report 2005; Ceredigion, Whales. 2006, pp. 5-21. Available online: http://www.strandings.com/Graphics\%20active/2005\%20Mammal\%20Strandings.pdf (accessed on 7 June 2021). 